\title{
Serotonin Immunoreactivity Is Contained in One Physiological Cell Class in the Rat Rostral Ventromedial Medulla
}

\author{
Sonja B. Potrebic, ${ }^{1,2}$ Howard L. Fields, ${ }^{2,3}$ and Peggy Mason ${ }^{2, a}$ \\ ${ }^{1}$ The Program in Neuroscience, Harvard Medical School, Boston, Massachusetts 02143 and 2Departments of Neurology, \\ Physiology, and ${ }^{3}$ the Keck Center for Integrative Neuroscience, University of California at San Francisco, San Francisco, \\ California $94143-0114$
}

Neurons in the rostral ventromedial medulla (RVM) are the major source of serotonergic projections to the dorsal horn. A large body of evidence implicates RVM serotonergic neurons in the modulation of spinal nociceptive transmission. Three physiological classes of RVM neurons, on, off, and neutral cells, are postulated to have different nociceptive modulatory effects on spinal nocifensor reflexes. This study was undertaken to determine which RVM cell class(es) contains 5-HT.

In anesthetized rats, RVM neurons were identified by their responses to noxious cutaneous stimuli, intracellularly labeled, and processed for 5-HT immunocytochemistry. Labeled neurons were examined with epifluorescence and imaged using a confocal laser microscope. A total of 25 RVM neurons were intracellularly labeled. No off $(n=9)$ or on ( $n$ $=8$ ) cells were serotonergic. Half of the neutral cells (4 of 8) demonstrated 5-HT immunoreactivity.

These results call for a reevaluation of the mechanisms of RVM modulatory influence on spinal cord nociceptive transmission. The finding that some neutral cells are serotonergic strongly suggests that serotonergic neutral cells are involved in the modulation of spinal nociceptive transmission. Additionally, inhibition of spinal nociceptive transmission by off cells is unlikely to involve $5-\mathrm{HT}$ release. Finally, since opioid administration does not alter the firing of RVM neutral cells, the results of the present study indicate that serotonergic RVM neurons do not directly mediate the effects of supraspinal opioids in the rat.

[Key words: raphe magnus, antinociception, opioid analgesia, 5-HT, indoleamine, state dependence]

An extensive body of evidence indicates that serotonergic neurons in the rostral ventromedial medulla (RVM) are important in modulating spinal nociceptive transmission and in mediating the analgesic effects of exogenous opioids (Basbaum and Fields, 1984; LeBars, 1988; Fields et al., 1991). The RVM is part of a

\footnotetext{
Received Apr. 15, 1993; revised Aug. 24, 1993; accepted Aug. 30, 1993.

This research was supported by U.S. Public Health Service Grant NS 21445 , the Bristol Myers Squibb Foundation, and the William M. Keck Foundation. We thank Drs. Yuh Nung and Lily Jan for use of their confocal microscope, and Janet Supar, Larry Ackerman, and Mechelle Williams for their technical assistance.

Correspondence should be addressed to Sonja Potrebic, Department of Neurology, Box 0114, UCSF, San Francisco, CA 94143-0114.

${ }^{a}$ Present address: Department of Pharmacological and Physiological Sciences and the Committee on Neurobiology, University of Chicago, 947 East 58th Street Chicago, IL 60637.

Copyright (C) 1994 Society for Neuroscience $0270-6474 / 94 / 141655-11 \$ 05.00 / 0$
}

well-documented nociceptive modulatory pathway to the dorsal horn, which includes the periaqueductal gray (PAG). The hypothesis that RVM 5-HT contributes to the inhibition of spinal nociceptive transmission is based on several independent lines of evidence. Activation of RVM neurons produces antinociception (Oliveras et al., 1975; Levy and Proudfit, 1979; Jensen and Yaksh, 1986; Jensen and Yaksh, 1989) and inhibits the nociceptive responses of dorsal horn cells (Fields et al., 1977; Sessle and Hu, 1981; Sessle et al., 1981). RVM serotonergic neurons are the major source of 5-HT in the spinal and trigeminal dorsal horns (Dahlstrom and Fuxe, 1964; Oliveras et al., 1977; Kwiat and Basbaum, 1992). Systemic administration of an agent that produces 5-HT depletion abolishes the long-latency component of dorsal horn neuronal inhibition produced by electrical stimulation within RVM (Rivot et al., 1980) and interferes with stimulation-produced antinociception from the PAG (Akil and Leibeskind, 1975). Systemically administered 5-HT antagonists can partially reverse the inhibition of spinothalamic tract neurons produced by electrical stimulation of RVM (Yezierski et al., 1982). Additionally, the elevation of tail flick latencies following RVM opioid (Jensen and Yaksh, 1986) or glutamate (Jensen and Yaksh, 1984) microinjection or electrical stimulation (Hammond and Yaksh, 1984; Barbaro et al., 1985 ) is partially reduced by intrathecal administration of $5-\mathrm{HT}$ antagonists.

5-HT in the spinal cord likely has an inhibitory effect on nociceptive transmission. Intrathecal administration of 5-HT (Yaksh and Wilson, 1979) produces hypoalgesia in a number of nociceptive tests. Iontophoretically applied 5-HT inhibits the spontaneous (Randic and Yu, 1976; Jordan et al., 1978; cf. Belcher et al., 1978) and evoked (Randic and $\mathrm{Yu}, 1976$; Belcher et al., 1978; Jordan et al., 1978) activity of many nociceptive neurons in the dorsal horn.

5-HT may mediate, at least in part, the antinociceptive effects of systcmic morphine. Within the spinal cord, synthesis (WeilFugazza et al., 1981), metabolism, and release (Shiomi et al., 1978; Vasko and Vogt, 1982) of 5-HT increase following systemic morphine administration. Depletion of spinal 5-HT by central administration of neurotoxins can attenuate opioid antinociception (Vogt, 1974; Deakin and Dostrovsky, 1978; Mohrland and Gebhart, 1980; Romandini et al., 1986).

However, it is important to note that studies concerning a direct contribution of medullospinal serotonergic neurons to opioid analgesia are inconsistent. The effects of 5-HT-selective neurotoxin treatment on both opioid antinociception and nociceptive responsiveness have varied among investigators (see 
Discussion, and LeBars, 1988). Furthermore, opioid administration has not been shown to have any effect on the activity of presumed serotonergic RVM neurons identified by electrophysiological or pharmacological methods (Auerbach et al., 1985; Chiang and Pan, 1985). Additionally, a recent study utilizing in vivo microdialysis in awake, behaving rats did not find a correlation between spinal 5-HT release and opioid antinociception (Matos et al., 1992).

The identification of three physiologically distinct cell groups in the RVM provides a framework in which to examine the role of serotonergic medullospinal neurons in nociceptive modulation. RVM neurons can be classified according to changes in activity evoked by noxious stimuli and opioid administration (Fields et al., 1983a,b; Barbaro et al., 1986; Cheng et al., 1986; cf. Chiang and Gao, 1986). Off cells increase their firing rate just prior to nociceptive withdrawal reflexes and become continuously active following systemic or supraspinal opioid administration. Although some investigators have not observed off cells in awake rats (Oliveras et al., 1990; Martin et al., 1992), recently McGaraughty et al. (1993) have demonstrated characteristic off-cell responses to systemic morphine in awake rats. On cells exhibit responses opposite to those of off cells; they increase their firing rate in response to noxious stimuli and are inhibited by morphine administration. A third group of cells, neutral cells, shows no consistent change in activity in response to noxious stimuli or opioid administration. Ncurons in cach cell group project to the spinal cord (Vanegas et al., 1984b). Off cells are hypothesized to have a net inhibitory effect on spinal nociceptive transmission, whereas on cells appear to exert a net facilitatory influence. The function of neutral cells in the modulation of spinal nociceptive transmission remains obscure (Fields et al., 1991).

In previous studies of RVM, neurons have been identified as serotonergic using indirect criteria such as spontaneous activity (Auerbach et al., 1985; Chiang and Pan, 1985; Fornal et al., 1985; Chiang and Gao, 1986), conduction velocity (Wessendorf and Anderson, 1983; Chiang and Pan, 1985; Chiang and Gao, 1986), and inhibition following 5-HT agonist administration (Fornal et al., 1985). The present study reports the results of experiments aimed to test directly which physiological type(s) of RVM cells contains 5-HT. Since (1) off cells are the only RVM neurons activated by systemic morphine (Fields et al., 1983b; Barbaro et al., 1986), (2) a significant number of off cells project to the spinal cord (Vanegas et al, 1984b), and (3) 5-HT metabolism appears to be increased during morphine analgesia (Shiomi et al., 1978; Weil-Fugazza et al., 1981; Vasko and Vogt, 1982), we had hypothesized that 5-HT is contained within off cells (Fields et al., 1991). However, the results reported here indicate that only RVM neutral cells contain 5-IIT.

\section{Materials and Methods}

Male Sprague-Dawley rats $(250-400 \mathrm{gm})$ were used in all experiments. Animals were initially anesthetized with sodium pentobarbital $(60 \mathrm{mg} /$ $\mathrm{kg}$, i.p.) and were maintained in a light anesthetic state on $0.5-1.0 \%$ halothane in oxygen.

Methods for physiological recording in rats have been described (Mason et al., 1990) and will be restated only briefly. Glass micropipettes (resistance of 30-80 M 2 ) were filled with a solution of $2 \%$ neurobiotin (Vector Laboratories, Burlingame, CA) in $0.1 \mathrm{M}$ Tris buffer ( $\mathrm{pH} 7.4)$ and $0.15 \mathrm{M} \mathrm{KCl}$. For each animal, electrode penetrations began rostrally in the brainstem, at sites ranging from interaural levels of approximately $-0.9 \mathrm{~mm}$ to $-2.2 \mathrm{~mm}$ (mean $-1.7 \mathrm{~mm}$ ), according to the atlas of Paxinos and Watson (1986), and proceeded caudally. Neurons were isolated by either spontaneous activity or resting membrane potential.
Neurons were characterized by their response to a thermal stimulus applied to the tail and to noxious pinches to the hindpaws, nose, and tail. Noxious pinch was applied by toothed forceps at a pressure that was judged painful by the experimenters. Only neurons with a consistent response to noxious stimuli applied to the tail, hindpaw, and nose were studied further. Neurons were labeled with neurobiotin by injecting constant depolarizing current $(0.5-4 \mathrm{nA})$ for $30 \mathrm{sec}$ to $15 \mathrm{~min}$.

Animals were killed with a pentobarbital overdose and perfused with $200 \mathrm{ml}$ of saline followed by 1 liter of a fixative containing $4 \%$ paraformaldehyde and $7 \%$ sucrose in $0.1 \mathrm{M}$ phosphate-buffered saline (PBS). The brainstem was removed, postfixed for $1 \mathrm{hr}$ in fixative, and cryoprotected overnight in $30 \%$ sucrose in $0.1 \mathrm{~m}$ PBS. Coronal serial 50 $\mu \mathrm{m}$ sections were cut on a freezing microtome.

Intracellular neurobiotin was visualized by reacting sections in $0.4 \%$ avidin (in $0.1 \mathrm{M}$ PBS, $0.5 \%$ Triton $\mathrm{X}-100$ ) conjugated to Texas red (Vector Laboratories) for $4 \mathrm{hr}$ at $4^{\circ} \mathrm{C}$. Sections containing labeled neurons were processed for 5-HT immunocytochemistry. Sections were protected from light at all times.

Rabbit anti-5-HT (Incstar, Stillwater, MN) was used at a final dilution of $1: 20,000$. Antiserum was diluted in $0.1 \mathrm{M}$ PBS containing $0.3 \%$ Triton $\mathrm{X}-100$ and $1 \%$ normal goat serum (NGS). Buffers for washing and dilution were the same unless noted. The diluted antiserum was incubated with $15-20 \mathrm{mg}$ of acetone-extracted rat liver powder overnight at $4^{\circ} \mathrm{C}$ and centrifuged to remove the precipitate.

The following steps were performed at $4^{\circ} \mathrm{C}$ on a shaker. Sections were incubated in $50 \%$ ethanol for $30 \mathrm{~min}$ and transferred into buffer for three $10 \mathrm{~min}$ washes. Tissue was incubated in a solution of $3 \%$ NGS, $0.1 \mathrm{M}$ PBS, and $0.3 \%$ Triton X-100 for $30 \mathrm{~min}$ before being transferred directly into the primary antibody solution for $48-72 \mathrm{hr}$. Sections were rinsed three times for $10 \mathrm{~min}$ in $50 \mathrm{ml}$ of PBS before being transferred to the secondary antibody solution (fluorescein goat anti-rabbit, 1:250; Vector Laboratories) or $10 \mu \mathrm{g} / \mathrm{ml}$ of Bodipy goat anti-rabbit (Molecular Probes, Eugene, OR) for 6-8 hr. Sections were washed once for $10 \mathrm{~min}$ in $50 \mathrm{ml}$ of PBS with $0.5 \%$ Triton X-100 and rinsed three times for 10 $\mathrm{min}$ in $50 \mathrm{ml}$ of PBS. Sections were mounted on unsubbed slides, coverslipped with $2 \% n$-propyl gallate in glycerol, and stored at $-20^{\circ} \mathrm{C}$.

Three types of control experiments were performed. 5-HT antiserum was incubated overnight with $100 \mu \mathrm{g} / \mathrm{ml}$ of a $5-\mathrm{HT}$-bovine serum albumin conjugate (Incstar). Preabsorbed antiserum substituted into the above protocol produced no specific staining. When the primary antibody was omitted from the staining protocol, neither Bodipy nor fluorescein-conjugated secondary antibody produced any specific staining.

The third control experiment examined RVM 5-HT immunoreactivity in rats pretreated with a 5-HT precursor and a monoamine oxidase inhibitor. Two rats were treated with tranylcypromine (Sigma, St. Louis, MO; $30 \mathrm{mg} / \mathrm{kg}$, i.p.) $90 \mathrm{~min}$ prior to perfusion, and tryptophan (Sigma; $300 \mathrm{mg} / \mathrm{kg}$, i.p.) $60 \mathrm{~min}$ prior to perfusion (M. Wessendorf, personal communication). Both rats exhibited signs of the 5-HT syndrome such as wet-dog shakes, piloerection, and moving of the head back and forth.

Sections from pretreated rats and two rats injected with saline were simultaneously processed for $5-\mathrm{HT}$ immunoreactivity. Eight $50 \mu \mathrm{m}$ sections were examined from each rat. Four sections were taken at the level of the facial nucleus, two sections each from approximately interaural -2.4 and -1.9 (Paxinos and Watson, 1986). Four sections were also taken from the level of the superior olivary nucleus, two sections each from interaural -1.0 and -0.8 . Tissue sections were examined on the confocal microscope. The number of RVM serotonergic neurons (cellular profiles with a diameter of greater than $10 \mu \mathrm{m}$ ) (Skagerberg and Bjorklund, 1985) was determined by a blinded experimenter using software provided by Bio-Rad. RVM was defined as containing nucleus raphe magnus $(\mathrm{RMg})$ and nucleus reticularis gigantocellularis pars alpha (GiA) based on previous descriptions in Paxinos and Watson (1986) and Andrezik and Beitz (1985). In each rat, one section from each of the four rostrocaudal levels was stained with cresyl violet. The total number of cellular profiles with a diameter of greater than $10 \mu \mathrm{m}$ (Skagerberg and Bjorklund, 1985) was then determined, either by using a calibrated ocular micrometer or by drawing somatic profiles at $300 \times$ magnification with a camcra lucida. The percentage of scrotoncrgic neurons at each rostrocaudal level was calculated by dividing the number of 5-HT-immunoreactive (5-HT-IR) cells per section by the number of cresyl violet-stained cells counted in that section.

For intracellularly labeled neurons, somata were examined on a Nikon Optiphot (60) objective) or Zeiss Axioplan ( $63 \times$ objective) microscope. Each soma was viewed with the Texas red filter (Nikon emission 605-658 nm, excitation 536-585 nm/Ziess filter set 00) and subse- 
A
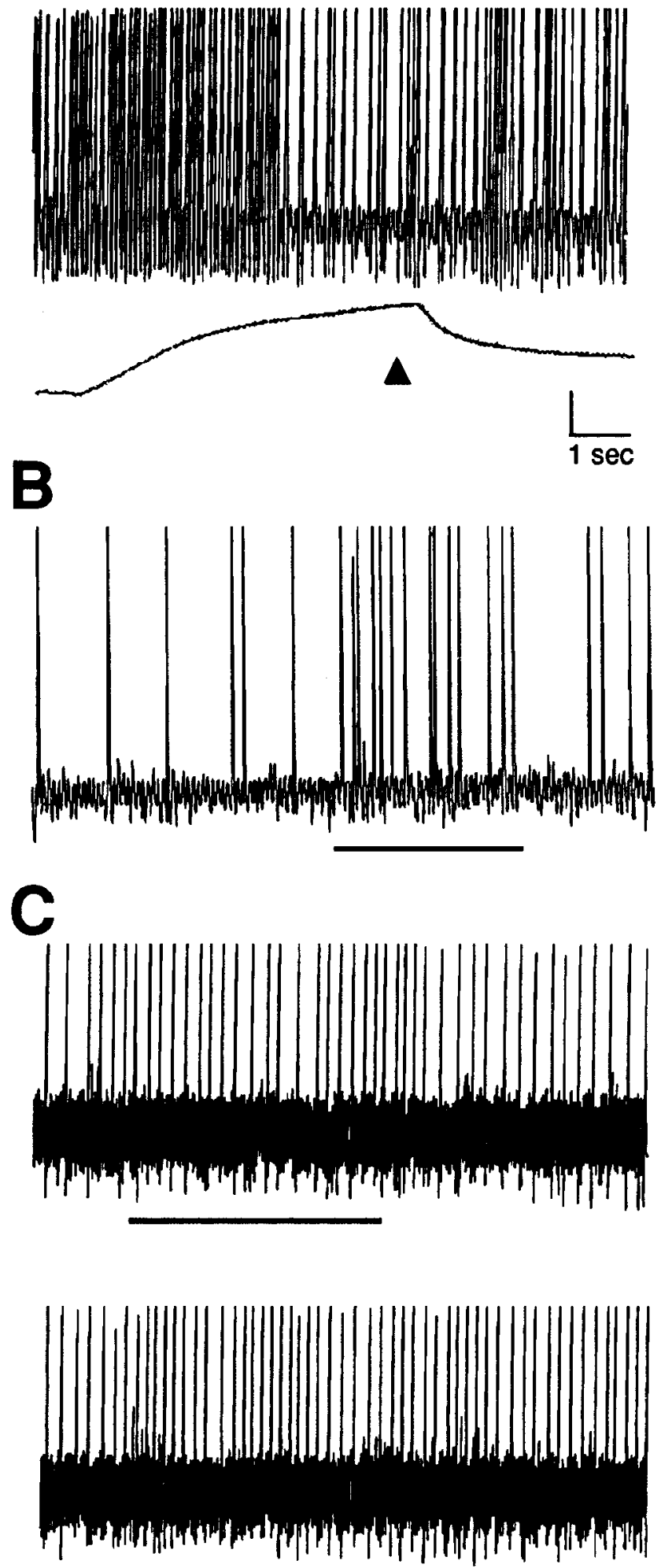

Figure 1. The intracellular responses of three classes of RVM neurons to noxious stimulation are shown. The top of the recordings is truncated since the height of the digitized action potential varies. $A$, An off cell (see Fig. $5 \mathrm{C}$ ) is inhibited by tail heat applied with a ramp stimulus (33$55^{\circ} \mathrm{C}$ ). The temperature trace is shown beneath the intracellular response. The occurrence of the tail flick is indicated by the triangle. $B$, An on cell (neuron not shown) is excited during the application of quently with a fluorescein filter (Nikon emission 505, excitation 465495/Zeiss filter set 10 ) to determine whether the neuron contained 5-HTlike immunoreactivity. No "bleed through" fluorescence was detected between the two filter sets.

These cells were part of a study that used the confocal scanning laser microscope to examine the distribution of serotonergic terminals onto labeled RVM cells. Therefore, images were captured using a Bio-Rad Confocal Laser Scanning microscope (MRC-600). Two systems, equipped with either an argon (A1 and A2 filter set) or krypton-argon (K1 and K2 filter set) laser, were used. The images obtained from both systems were comparable.

Individual optical images were acquired in $1-1.5 \mu \mathrm{m}$ steps through the tissue. With the high-power objectives, the confocal apertures were set so that the optical section thickness was $1.5-2.1 \mu \mathrm{m}$. For low-power objectives, tissue was imaged throughout a depth of field of more than $20 \mu \mathrm{m}$. Both fluorophors were visualized simultaneously at each optical level.

To compare the somatic characteristics of serotonergic neutral cells with the general RVM 5-HT neuronal population, 20 non-intracellularly labeled 5-HT-IR neurons were chosen by an observer unfamiliar with the experiment. Five 5-HT neurons were chosen from tissue adjacent to sections containing each serotonergic neutral cell. Total somatic length and cross-sectional area were determined from projected images (see below) using software provided by the manufacturer (Bio-Rad). The border between the soma and primary dendrites was defined as the inflection point where the primary dendrite emerged from the curvature of the somatic surface. Total somatic surface area was calculated from measurements of somatic perimeter taken every $1-3 \mu \mathrm{m}$ throughout tissue where the soma was present. Surface area was calculated as perimeter times the distance between optical sections. Sections that contained the top or bottom of the soma contributed both a perimeter element and surface area measurement.

All photos were obtained from the confocal images. The pictures have been intensity adjusted for presentation. The figures are maximal projections, constructed from a stack of $4-40$ serial confocal optical images. In this type of projection, the pixel intensity at any point represents the maximum pixel intensity, found at that $x-y$ location, present in the z-axis series of confocal optical slices.

Mann-Whitney $U$ tests were performed with the aid of STATVIEW 4.0 (Abacus Concepts, Berkeley, CA). The $p$ values from the Fisher exact probability tests were determined from $2 \times 2$ tables using a calculator.

\section{Results}

Physiology

RVM neurons were classified as ofl, on, or neutral cells according to the qualitative changes in neuronal firing observed during the heat-evoked tail flick reflex and in response to noxious pinch of the nose, hindpaw, and tail. Off cells decreased and on cells increased their firing rate in response to noxious tail heat and pinch (Fig. 1). Only cells with changes in neuronal firing that were related to the stimulus presentation and were consistent in sign, regardless of the stimulus location, were classified as on or off cells. Neutral cells exhibited no sustained change in firing rate in response to tail heat or noxious pinch applied anywhere on the body surface. Among cells not excited by noxious stimulation, only spontaneously active units were studied, in order to differentiate between off and neutral cells.

\section{5-IIT immunoreactivity}

5-HT-IR neurons were found throughout the RVM: in the RMg and in the adjacent medullary reticular formation dorsal to the pyramids (Fig. 2). 5-HT-IR cells were concentrated near the

\footnotetext{
noxious pinch to the nose. $C$, There is no change in the activity of this nonserotonergic neutral cell (see Fig. $4 D$ ) during hindpaw pinch (upper trace) and tail pinch (lower trace). In $B$ and $C$ the bar denotes the application of the stimulus. Voltage calibration: $10 \mathrm{mV}$ for $A$ and $B, 5$ $\mathrm{mV}$ for $C$.
} 


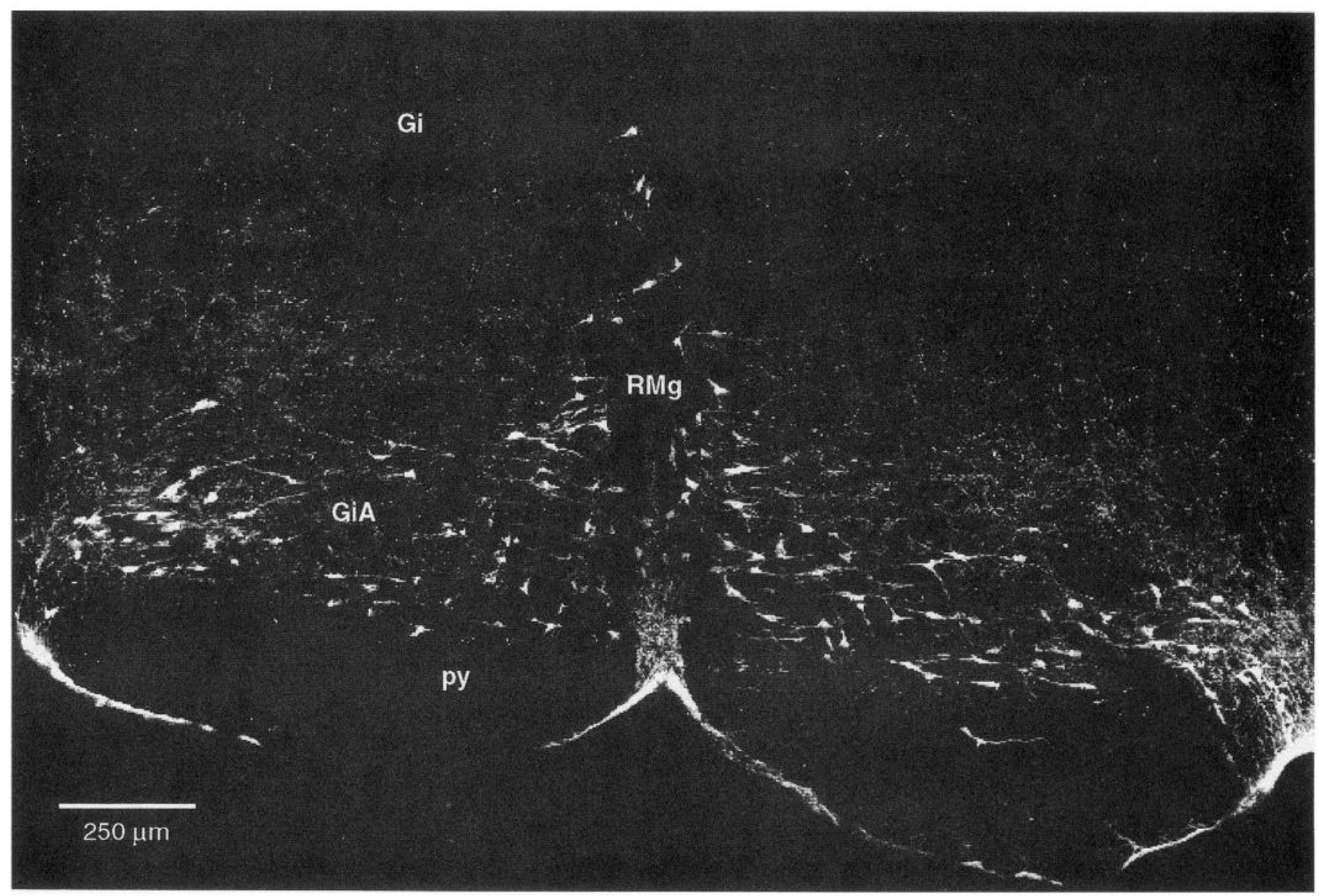

Figure 2. The distribution of 5-HT-IR neurons is shown in this low-power montage of RVM at the level of the caudal facial nucleus. The image is composed of four low-power confocal projections taken from a $50 \mu \mathrm{m}$ brainstem section. $R M g$, nucleus raphe magnus; $G i$, nucleus gigantocellularis; GiA, nucleus reticularis gigantocellularis pars alpha; $p y$, pyramidal tract.

midline and on the ventral margins of GiA (Paxinos and Watson, 1986). Somatic measurements were made for 20 nonintracellularly labeled 5-HT-IR neurons (see last column of Fig. 6). RVM 5-HT neurons had a median somatic length of $26.6 \mu \mathrm{m}$

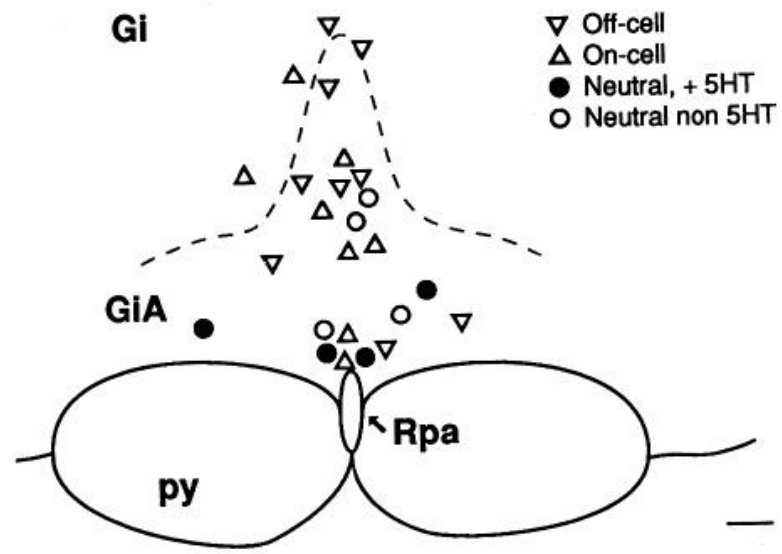

Figure 3. The locations of the 25 intracellularly labeled neurons are plotted on this schematic of RVM. The dashed line represents the outline of the RVM region containing serotonergic neurons. $R M g$, nucleus raphe magnus; $G i$, nucleus gigantocellularis; $G i A$, nucleus reticularis gigantocellularis pars alpha; $p y$, pyramidal tract; $R p a$, nucleus raphe pallidus. Scale bar, $100 \mu \mathrm{m}$. (range, 15.5-44.2 $\mu \mathrm{m}$ ), median cross-sectional area of $263 \mu \mathrm{m}$ (range, 152-459 $\mu \mathrm{m}$ ), and a median somatic surface area of 920 $\mu \mathrm{m}$ (range, 678-1641 $\mu \mathrm{m}$ ). Cells located along the midline tended to be larger than neurons found more laterally in this region.

Pretreating rats with a 5-HT precursor and a monoamine oxidase inhibitor had no discernible effect on 5-HT immunoreactivity. Qualitatively, 5-HT immunoreactivity did not correlate with pretreatment. The number of RVM 5-HT-IR neurons varied $25 \%$ or less among the saline (counts of 397,363 ) and pretreated $(301,347)$ rats. Pretreatment also did not have any discernible effect on the percentage of all RVM neurons that were 5-HT-IR. The overall percentage of 5-HT neurons in RVM was remarkably similar between pretreated $(18.1 \%, 18.0 \%)$ and saline-treated $(15.5 \%, 17.3 \%)$ rats. The percentage of RVM neurons that were 5-HT-IR did vary slightly with the anteriorposterior level examined. At the level of the facial nucleus, $17.1 \%$ (range, $12.4-20.2 \%$; interaural -2.4 ) to $15.6 \%(14.4-$ $17.4 \% ;-1.9)$ of all RVM neurons contain 5-HT. At the level of the superior olivary nucleus, $21.2 \%(14.6-25.6 \% ;-1.0)$; and $17.0 \%(14.0-20.2 \% ;-0.8)$ of the RVM neurons are 5-HT-IR.

\section{Intracellular label}

Twenty-five RVM neurons were physiologically classified and intracellularly labeled in this study. The appearance of the intracellularly labeled on and off cells matched previous descrip- 

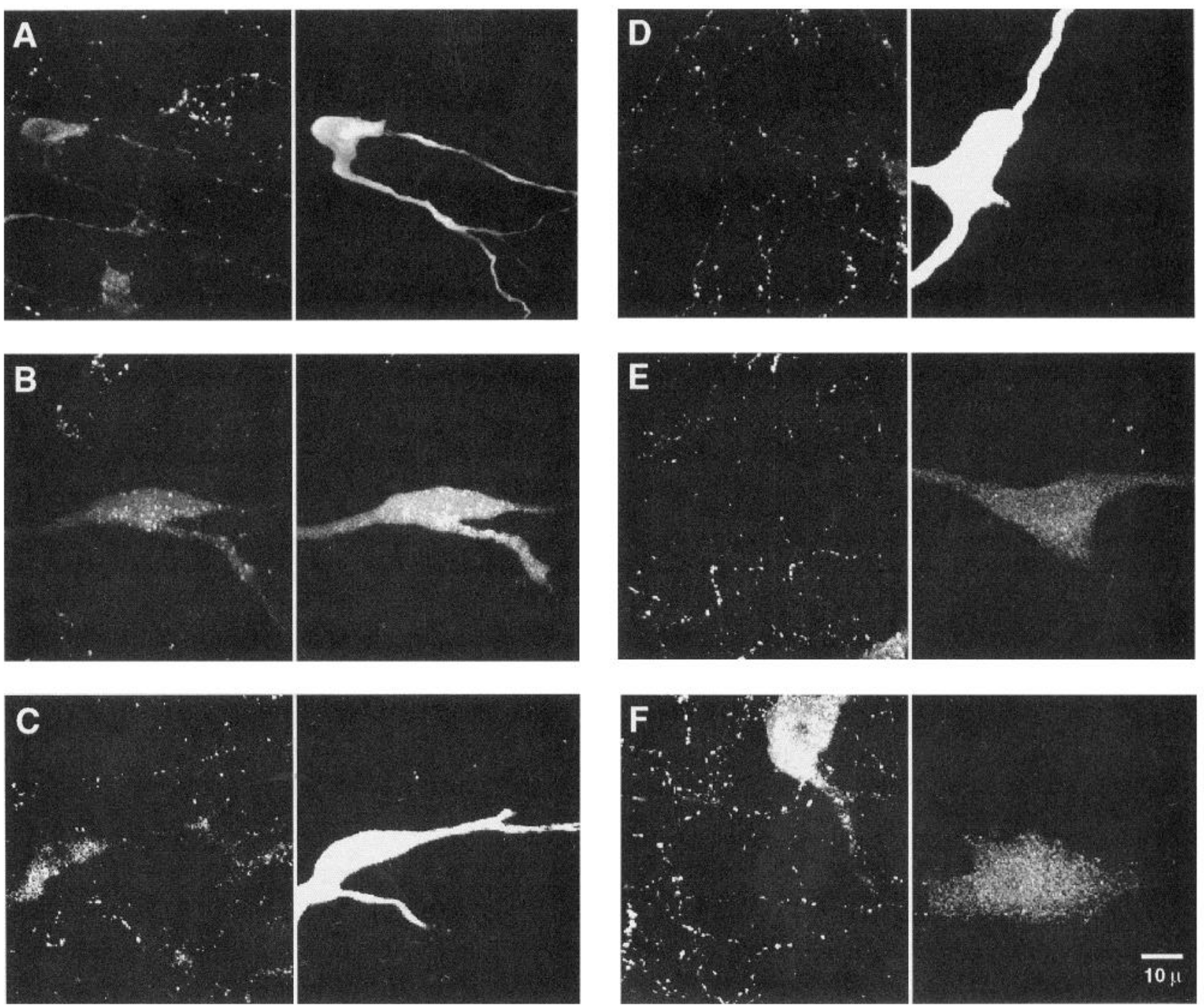

Figure 4. 5-HT immunocytochemistry of intracellularly labeled neutral cells. In each panel, 5-HT-IR staining is shown to the left, and the intracellular label to the right. $A-C$, Serotonergic neutral cells. $D-F$, Nonserotonergic neutral cells.

tions of these neuronal cell classes (Mason et al., 1990). Neurons had multipolar or fusiform somas, and the dendrites of welllabeled cells extended mediolaterally across RVM. Some intracellularly labeled neurons had identifiable axons. The majority of labeled cells were found in RVM at the level of the facial nucleus, at interaural levels ranging from $-2.6 \mathrm{~mm}$ to -1.5 $\mathrm{mm}$ (according to the atlas of Paxinos and Watson, 1986), within $300 \mu \mathrm{m}$ of the midline (Fig. 3). A single off cell was located at the caudal pole of $\mathrm{RMg}$, within $100 \mu \mathrm{m}$ of the rostral border of the inferior olivary nucleus.

\section{5-HT immunoreactivity of intracellularly labeled cells}

5-HT immunoreactivity was present in the somata and dendrites of four of the eight intracellularly labeled neutral cells (Fig. 4). In contrast, no off cells $(n=9)$ or on cells $(n=8)$ demonstrated 5-HT immunoreactivity (Fig. 5). An axonal collateral was observed for one off cell (not shown). Neither this collateral nor any of its en passant boutons showed 5-HT immunoreactivity. The distribution of serotonergic immunoreactivity in the neutral cell group differed significantly from the distribution found in both on cells $(p=0.038$, Fisher exact probability test) and off cells ( $p=0.029$, Fisher exact probability test).

The intracellularly labeled serotonergic neutral cells tended to be smaller than the other three intracellularly labeled cell groups in two of the three morphometric characteristics measured: cross-sectional area and total surface area (see Fig. 6). Serotonergic intracellularly labeled cells were significantly smaller than the nonserotonergic intracellularly labeled neurons in crosssectional area (Mann-Whitney $U$ test, $p=0.0187$ ) and total surface area (Mann-Whitney $U$ test, $p=0.0231$ ).

There was no significant difference between the intracellularly labeled 5-HT neutral cell group and our sample of 20 nonfilled RVM 5-HT neurons on any of the three somatic comparisons made (Mann-Whitney $U$ test, $p=0.8769$, length; $p=0.3526$, cross-sectional area; $p=0.1632$, surface area). The non-intracellularly labeled RVM 5-HT neurons were significantly smaller in somatic length (Mann-Whitney $U$ test, $p=0.0445$ ), crosssectional area (Mann-Whitney $U$ test, $p<0.0001$ ), and total surface area (Mann-Whitney $U$ test, $p=0.0124$ ) than the nonserotonergic intracellularly labeled neurons in our sample (Fig. $6 C)$. 

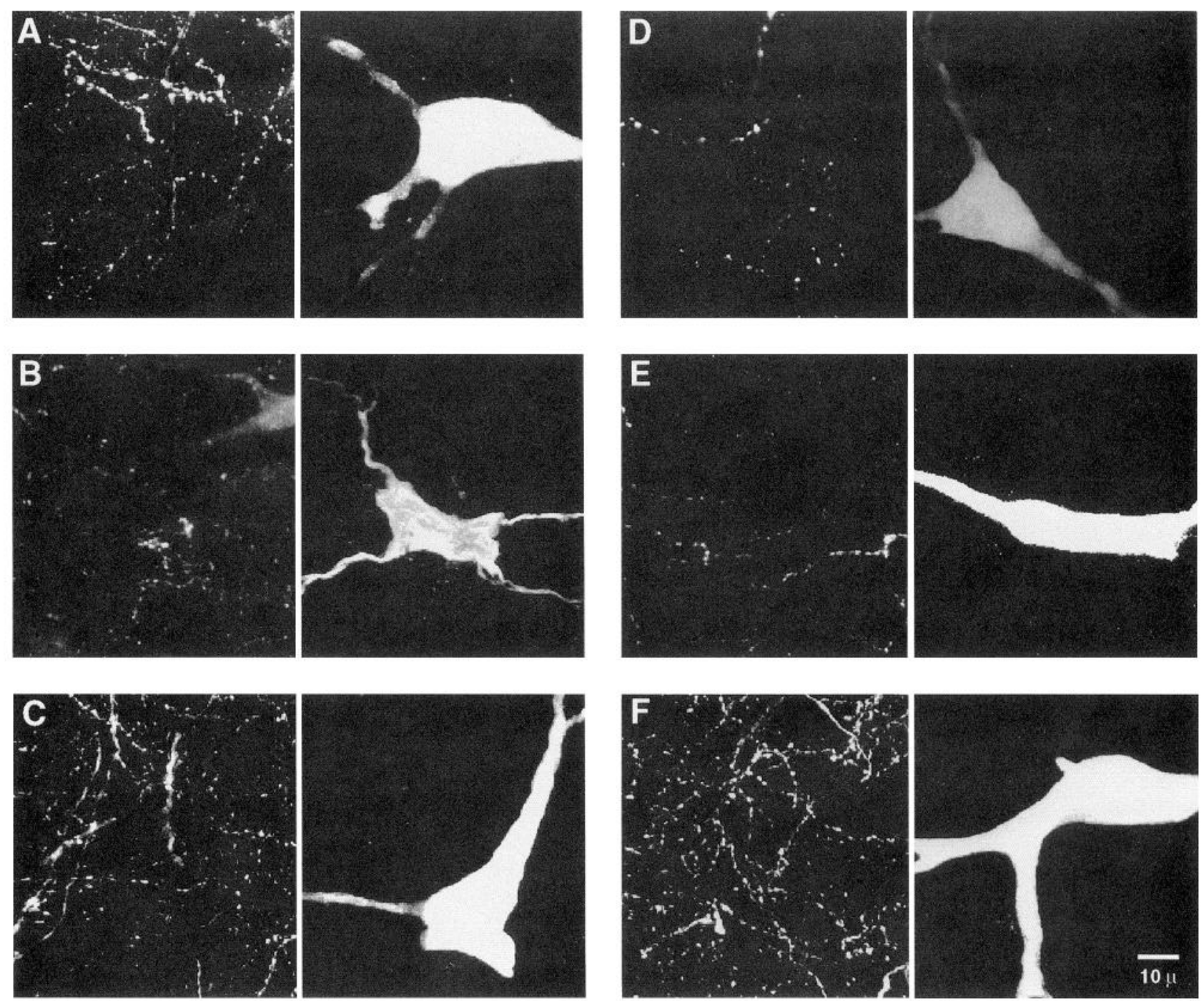

Figure 5. 5-HT immunocytochemistry of on and off cells. For each panel, 5-HT-IR staining is shown to the left, and the intracellular label to the right. $A-C$, Off cells. $D-F$, On cells.

\section{Discussion}

While many different lines of evidence point to a role for 5-HT in descending nociceptive modulation and opioid analgesia, understanding the mechanism by which this neurotransmitter functions has been hampered by the lack of a direct demonstration of the response characteristics of serotonergic neurons. In this study, 5-HT immunocytochemistry was combined with intracellular labeling to determine which of the three physiological cell groups described in RVM contains 5-HT.

In a sample of 25 intracellularly labeled neurons, all four 5-HT-IR cells are neutral cells. No off or on cells contain 5-HT even though these intracellularly labeled neurons are located in regions of RVM containing serotonergic cells. Given the small sample size, we cannot exclude the possibility that some on or off cells contain 5-HT. However, since the distribution of 5-HT immunoreactivity differs significantly between the neutral cell population $(50 \%)$ and on and off cells $(0 \%)$, the number of on and off cells containing 5-HT is likely to be quite small in comparison to the whole on- and off-cell population. Since off and neutral cells without spontaneous activity as well as neurons with mixed responses to noxious stimuli applied to different body regions were not studied, we do not know whether such neurons are serotonergic.

The relatively restricted location of the intracellularly labeled neutral cells within ventral RVM, as compared to the more widespread location of labeled on and off cells, may reflect our tendency to use the presence of on and off cells as an electrophysiological marker for the dorsal border of RVM. The clustering of intracellularly labeled serotonergic neutral cells in the ventral portion of RVM does not reflect the distribution of 5-HT-IR neurons (see Figs. 2, 3) or the regional location of all intracellularly labeled cells. It is, furthermore, unlikely that sampling bias based on neuronal size occurred; a comparison of the somatic features of nonfilled 5-HT-IR neurons with all intracellularly labeled cells shows that the physiologically characterized neurons span the range of sizes of the population of serotonergic RVM neurons.

\section{Comparison with previous results}

Our finding that RVM neutral cells, neurons that show no change in activity following noxious cutaneous stimuli, are serotonergic is in partial agreement with previous studies using indirect, electrophysiologic criteria to identify presumptive serotonergic 
RVM neurons. For example, in the anesthetized rat, putative 5-HT units identified by antidromic conduction velocity showed excitatory and inhibitory responses, as well as no response, to cutaneous noxious and innocuous stimuli (Wessendorf and Anderson, 1983). In the awake cat, presumptive 5-HT units were identified according to criteria established in the dorsal raphe (slow, steady discharge rate, wide extracellular action potential, inhibition by application of a serotonergic agonist). Some, but not all, of these cat 5-HT cells had excitatory responses to noxious and non-noxious sensory stimulation. In agreement with the present results, most putative 5-HT neurons in $\mathrm{RMg}$ ( 15 of 16) wcre unaffected by an analgesic dose of systemic morphine (Auerbach et al., 1985; Fornal et al., 1985). Additionally, in the anesthetized rat, 6 of 10 presumed serotonergic neurons characterized by conduction velocity and rate of spontaneous activity did not show any change in activity following systemic administration of morphine (Chiang and Pan, 1985)

The most reliable current method of determining neurotransmitter content involves a direct demonstration (e.g., immunocytochemistry) that the neuron being studied contains $5-\mathrm{HT}$. In one previous study where 5-HT immunocytochemistry was performed on physiologically characterized cat RVM cells, neurons that were orthodromically excited by PAG stimulation did not contain 5-HT immunoreactivity (Mason et al., 1988). Since in the rat both on and off cells are activated by antinociceptive levels of electrical PAG stimulation (Vanegas et al., 1984a), it is likely that the nonserotonergic cat neurons studied included on and off cells. However, because the effect of electrical PAG stimulation on neutral cells has not been examined, the findings of Mason et al. (1988) cannot be directly compared to those of the present study.

Recently, Pan et al. (1993) recorded intracellularly from cells in the rat RVM slice and examined the 5-HT immunoreactivity of labeled neurons. Based upon their classification scheme, the majority (9 of 10) of "secondary" cells, neurons that are directly hyperpolarized by opioids, did not demonstrate 5-HT immunoreactivity. Since "secondary" neurons likely correspond to "on cells" in the Fields classification (Heinricher et al., 1992), this result of the Pan et al. (1993) study is consistent with the present finding that none of the intracellularly labeled on cells were 5-HT-IR.

Pan et al. (1993) also observed that almost all "primary" neurons, cells that are disinhibited by opioids, were 5-HT-IR. Neurons that are disinhibited by opioids in the slice are likely to include neurons that correspond to off cells in the in vivo preparation. However, the fact that they lack a direct response to opioids means that this group of primary neurons could represent a population that includes both neutral and off cells. In either case, the high proportion (93\%) of 5-HT immunoreactivity found by Pan et al. (1993) in "primary" cells is in apparent conflict with the present findings.

Beyond the obvious alterations in circuitry that occur in the process of preparing the RVM slice, there are two major differences between the two studies' methods that may account for the conflicting results. First, the RVM slices in the Pan et al. (1993) study were taken from the rostrocaudal level of the superior olivary complex, whereas the in vivo recordings presented here were made at the level of the facial nucleus. It is possible that on, off, and neutral cells differ in their neurochemistry along the rostrocaudal axis such that on and off cells located more rostrally in the brainstem are more likely to contain 5-HT.

A second difference between the studies is that the slices were loaded with tryptophan, a 5-HT precursor, and treated with
A
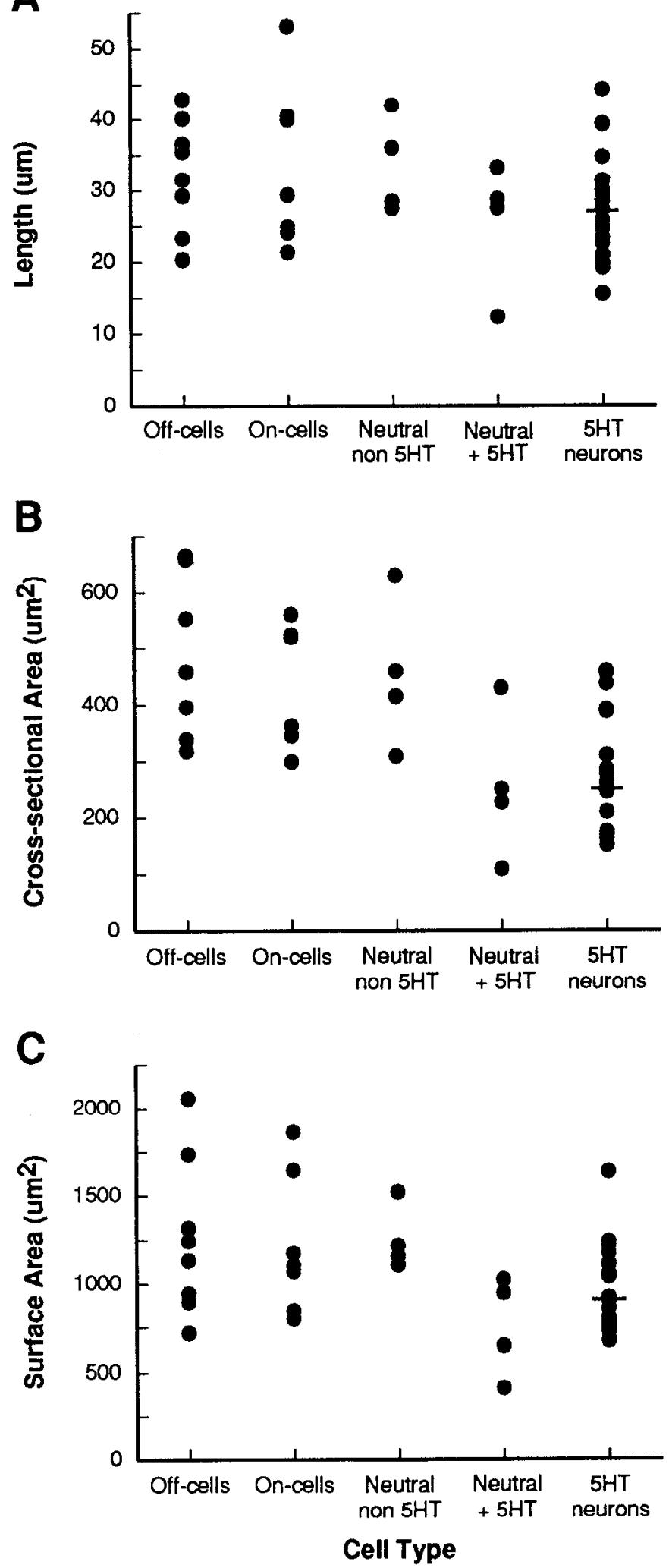

Figure 6. Scatter graphs show the range of somatic measurements taken from 23 intracellularly labeled neurons (eight off, seven on, four nonserotonergic, and four serotonergic neutral cells) and 20 nonintracellularly labeled RVM 5-HT-IR neurons. Each neuron is represented by a circle. In the last column, the line represents the median somatic value for the nonlabeled RVM 5-HT-IR neurons. 
pargyline, a monoamine oxidase inhibitor, whereas our 5-HT immunostaining of physiologically identified cells was carried out in untreated rats. It is unlikely that we missed a significant population of 5-HT-IR neurons because of low levels of 5-HT since we found no qualitative or quantitative difference between the 5-HT immunoreactivity in pretreated versus untreated rats. In contrast, RVM slices that were not loaded prior to histochemical processing often lacked 5-HT-IR cells (Wessendorf, personal communication).

A previous study suggests that caution must be uscd in the interpretation of 5-HT immunoreactivity in tissue exposed to high levels of tryptophan and a monoamine oxidase inhibitor (Wallace et al., 1982). In some cases, this type of treatment may result in the appearance of 5-HT immunoreactivity in neurons that are not serotonergic. In the Wallace et al. study, 5-HT immunoreactivity that appeared in dopaminergic neurons only following in vivo pretreatment with L-tryplophan and nialamide could be blocked by pretreatment with a catecholaminergic reuptake blocker. No similar study has examined the effect of tryptophan and a monoamine oxidase inhibitor on 5-HT immunoreactivity in a slice preparation. In the Pan et al. (1993) study, 27 of 38 (71\%) intracellularly labeled neurons demonstrated 5-HT immunoreactivity. This result may indicate that recordings were made preferentially from serotonergic neurons. However, the possibility of false positive 5-HT-IR neurons seems significant. Our own data suggest that the median percentage of 5-HT-IR neurons in this region is $19.7 \%$ (range, 14-25.6\%). Our figures are in agreement with a previous estimate that serotonergic neurons represent $10-30 \%$ of the rostral medullary cell population (Moore, 1981).

\section{5-HT and opioid analgesia}

Our present results suggest that serotonergic neutral cells do not directly mediate the antinociceptive effects of opioids in the anesthetized rat, since systemic (Barbaro et al., 1986) or local PAG (Cheng et al., 1986) administration of morphine does not affect the spontaneous firing of neutral cells. This finding calls for a reevaluation of the mechanisms by which RVM modulates spinal nociceptive transmission and raises questions about the involvement of serotonergic RVM neurons in mediating the effects of systemic opioids. Previous studies have suggested that serotonergic RVM neurons mediate the antinociceptive effects of opioids. However, experimental support for this straightforward hypothesis is controversial.

Depletion of 5-HT by chemical pretreatment has no consistent effect on the antinociception produced by systemic morphine (LeBars, 1988). Neurotoxin-induced 5-HT depletion has been shown to have no effect on morphine analgesia in the tail flick (Bodnar et al., 1981; Dennis and Melzack, 1983) and hot plate test (Dennis and Melzack, 1983); to attenuate the effect of morphine in the formalin test (only at high $p$-chlorophenylalanine doses; Dennis and Melzack, 1983), the jump flinch test (Bodnar et al., 1981; Berge et al., 1983), paw withdrawal (Vogt, 1974), and the hot plate and tail flick test (Berge et al., 1983); and to facilitate the effect of low-dose morphine on the formalin test (Dennis and Melzack, 1983).

Studies examining the relationship between opioid administration, behavior changes, and spinal 5-HT metabolism have also yielded inconsistent results. Subcutaneous morphine was shown to increase the synthesis of 5-HT, in both the dorsal and ventral horn of the spinal cord, although the development of behavioral analgesia preceded the increase in 5-HT synthesis in this study (Weil-Fugazza et al., 1981). Systemic morphine was reported to increase the levels of the 5-HT metabolite 5-hydroxyindoleacetic acid (5-HIAA), measured fluorometrically or with HPLC, in the spinal cord (Shiomi et al., 1978; Vasko and Vogt, 1982). However, using in vivo voltammetry, changes in 5-HT metabolism following opioid administration are seen only in awake rats (Rivot et al., 1988). Recently, in vivo microdialysis has been used to examine changes in serotonergic metabolism following morphine administration (Matos et al., 1992). Following systemic or intraventricular morphine or DAMGO administration, no consistent changes werc found in 5-HT or 5-HIAA levels in the spinal cord of awake rats showing signs of behavioral analgesia.

Results of studies utilizing intrathecal 5-HT antagonists to examine the role of spinal serotonergic transmission in mediating opioid analgesia have also been difficult to interpret. For example, although intrathecal methysergide reduces the elevation in lail flick latencies following morphine microinjection into the PAG or RVM, a similar effect was not seen in the hot plate response (Jensen and Yaksh, 1986).

The inconsistencies in the published literature concerning the contribution of serotonergic transmission to opioid-induced analgesia combined with our demonstration that only a subgroup of neutral cells in our sample of RVM neurons were serotonergic suggest that if spinal 5-HT derived from RVM does have a role in mediating the behavioral effects of opioids, then the mechanism is likely to be complex. For example, even though neutral cell activity is unchanged by opioid administration (Barbaro et al., 1986; Cheng et al., 1986), serotonergic neutral cells may still be indirectly involved if the release of 5-HT has a permissive effect on opioid analgesia. In this case, the inhibitory effect of descending off-cell axons, excited by supraspinal opioids, may require the tonic activity of serotonergic RVM cells.

Alternatively, even though RVM neutral cell activity is unchanged by opioid administration (Barbaro et al., 1986; Cheng et al., 1986), this lack of change in neuronal firing does not preclude the possibility of changes in 5-HT release at the spinal cord level. Jacobs and colleagues have speculated that changes in 5-HT release may occur independently from changes in neuronal firing (Jacobs et al., 1990; Jacobs and Fornal, 1991). Thus, descending off-cell axons excited by supraspinal opioids could promote the release of 5-HT from neutral cell terminals in the spinal cord, independent of the firing of neutral cell somata. The interaction between off- and neutral-cell terminals could be either by convergent input to dorsal horn neurons via axoaxonic synapses (Ruda and Gobel, 1980) or by a parasynaptic effect (Herkenham, 1987; Bredt and Snyder, 1992; Valtschanoff et al., 1992).

\section{Mechanism of off-cell inhibition}

Off cells are hypothesized to have a net inhibitory effect on spinal nociceptive transmission. This hypothesis is based largely upon their projection to the spinal cord and the effect of opioid agonists and antagonists on their discharge rates (Fields et al., 1991). Previous speculation on the mechanism by which off cells inhibit spinal nociceptive transmission was based upon the finding that opioids evoke 5-HT release in the spinal cord (Fields et al., 1991). The present results demonstrate that off-cell inhibition of spinal nociceptive transmission is not directly mediated by 5 -HT.

There is ample evidence for a nonserotonergic component to RVM's descending inhibition. The antinociceptive effects of electrical stimulation are only partially reversed by intrathecal 5-H' antagonists (Hammond and Yaksh, 1984; Barbaro et al., 
1985). The short latency of the earliest RVM-evoked inhibition of dorsal horn neurons (Light et al., 1986) indicates transmission by myelinated fibers. Since virtually all rat serotonergic fibers are unmyelinated (Basbaum et al., 1988), this effect is at least partially transmitted by nonserotonergic axons. In support of this idea, serotonergic neurotoxin pretreatment eliminates longlatency inhibition of dorsal horn neuronal firing, but does not affect short-latency inhibition (Rivot et al., 1980).

\section{The function of RVM serotonergic neutral cells}

RVM neutral cells are clearly a heterogeneous group including both serotonergic and nonserotonergic cells. It is possible that nonserotonergic neutral cells do not participate in nociceptive modulation under any circumstances. However, the extensive body of evidence implicating 5-HT in some of the inhibitory effects of RVM stimulation suggests that serotonergic neutral cells are likely to be involved in the descending modulation of spinal nociceptive transmission. Since 5 -HT is found only in neutral cells, and since RVM provides serotonergic input to the dorsal horn (Oliveras et al., 1977; Kwiat and Basbaum, 1992), it is likely that a significant number of RVM spinal neurons are serotonergic neutral cells.

It is possible that some or all of the neurons that are characterized as "neutral cells" would have radically different properties in the unanesthetized preparation. For instance, Oliveras et al. (1991) have reported that some "on cells" in the awake animal become unresponsive to somatic stimulation after Brevital administration. However, four of five cells that were unresponsive to somatic stimulation in the awake animal remained unresponsive following Brevital administration, evidence that at least some neutral cells have the same response properties in the awake and anesthetized state.

Recently, McGaraughty et al. (1993) reported that all units $(n=20)$ studied in the awake rat were either activated or inhibited by systemic morphine. This result indicates that characteristic on- and off-cell, but not neutral-cell-type, responses are present in the awake preparation. In contrast, Martin et al. (1992) found cells in awake rats that were unresponsive to noxious peripheral stimulation and also unresponsive to systemic morphine, evidence that neutral cell activity can be found in the awake animal (see also Auerbach et al., 1985; Fornal et al., 1985). The discrepancies between the results of these two studies might be attributed to differences in "stress levels" and acclimation to the experimental setup. In the Martin study, noxious stimuli were applied to the rats by the experimenters, whereas in the McGaraughty study, no noxious stimuli were applied and the experimenters were often "out of view" during the experiment. The stress induced by handling animals during experimentation may produce spontaneous neutral cell activity that is not present in nonstressed animals (see below).

Brainstem serotonergic neurons, including those located in RVM, are implicated in the modulation of behavioral state (Fornal and Jacobs, 1988). Cat RMg cells that are physiologically characterized as containing 5-HT are more active during alert waking than during quiet waking and are least active during slow wave sleep (Fornal et al., 1985). In the awake cat, these same (presumed) RMg 5-HT cells are unaffected or only weakly excited by somatic stimulation and are unaffected by analgesic doses of morphine (Auerbach et al., 1985). In anesthetized rats, the spontaneous and evoked activity of most RVM neurons, uncharacterized according to their 5-HT content, has been shown to be higher during desynchronized EEG periods than during synchronized periods (Grahn and Heller, 1989). These studies demonstrate that RVM neurons, perhaps including both serotonergic and nonserotonergic cells, have activity patterns that are correlated with EEG activity patterns and possibly bchavioral state.

Stress may produce a behavioral state during which 5 -HT cells are activated and 5-HT is released centrally. For example, in the awake cat, restraint, a common stressor, activates putative 5-HT cells in RMg (Auerbach et al., 1985). Behavioral studies demonstrate that the baseline tail flick latencies of naive awake rats are reduced by intrathecal methysergide, an effect not seen in rats habituated to the testing situation (Gamble and Milne, 1990). Similarly, 5-HT depletion reduces the tail flick latencies of naive rats but not of habituated rats (Gamble and Milne, 1990). These results suggest that in nonhabituated rats, "stress" due to handling activates RVM 5-HT cells and evokes release of spinal 5-HT, which in turn lowers nociceptive responsiveness. However, since stress typically produces an active waking state, it may be difficult to separate the effect of stress from the effect of an active versus quiet waking state. Future experiments will need to address whether and how serotonergic neutral cells participate in the state- and stress-related modulation of nociception.

\section{References}

Akil H, Liebeskind JC (1975) Monoaminergic mechanisms of stimulation-produced analgesia. Brain Res 94:279-296.

Andrezik JA, Beitz AJ (1985) Reticular formation, central gray and related tegmental nuclei. In: The rat nervous system, Vol 2, Hindbrain and spinal cord (Paxinos G, ed), pp 1-28. New York: Academic.

Auerbach S, Fornal C, Jacobs BL (1985) Responses of serotonincontaining neurons in nucleus raphe magnus to morphine, noxious stimuli, and periaqueductal gray stimulation in freely moving cats. Exp Neurol 88:609-628.

Barbaro NM, Hammond DL, Fields HL (1985) Effects of intrathccally administered methysergide and yohimbine on microstimulation-produced antinociception in the rat. Brain Res 343:223-229.

Barbaro NM, Heinricher MM, Fields HL (1986) Putative nociceptive modulatory neurons in the rostral ventral medulla: reflex activity predicts effects of morphine. Brain Res 366:203-210.

Basbaum AI, Fields HL (1984) Endogenous pain control systems: brainstem spinal pathways and endorphin circuitry. Annu Rev Neurosci 7:309-328.

Basbaum AI, Zahs K, Lord B, Lakos S (1988) The fiber caliber of 5-HT immunoreactive axons in the dorsolateral funiculus of the spinal cord of the rat and cat. Somatosens Mot Res 5:177-185.

Belcher G, Ryall RW, Schaffner R (1978) The differential effects of 5-hydroxytryptamine, noradrenaline, and raphe stimulation on nociceptive and non-nociceptive dorsal horn interneurones in the cat. Brain Res 151:307-321.

Berge O, Hole K, Orgen S (1983) Attenuation of morphine-induced analgesia by $p$-chlorophenylalanine and $p$-chloroamphetamine: testdependent effects and evidence for brainstem 5-hydroxytryptamine involvement. Brain Res 271:51-64.

Bodnar RJ, Kordover JH, Wallace MM, Tamie H (1981) Stress and morphine analgesia following $p$-chlorophenylalanine. Pharmacol Biochem Behav 14:645-651.

Bredt DS, Snyder SH (1992) Nitric oxide, a novel neuronal messenger. Neuron 8:3-11.

Cheng ZF, Fields HL, Heinricher MM (1986) Morphine microinjected into the periaqueductal gray has differential effects on 3 classes of medullary neurons. Brain Res 366:203-210.

Chiang CY, Gao B (1986) The modification by systemic morphine of the responses of serotonergic and non-serotonergic neurons in nucleus raphe magnus to heating the tail. Pain 26:245-257.

Chiang CY, Pan ZZ (1985) Differential responses of serotonergic and non serotonergic neurons in nucleus raphe magnus to systemic morphine in rats. Brain Res 332:146-150.

Dahlstrom A, Fuxe K (1964) Evidence for the existence of monoamine-containing neurons in the central nervous system. I. Demonstration of monoamine in the cell bodies of brain stem neurons. Acta Physiol Scand [Suppl] 232:1-36. 
Deakin JFW, Dostrovsky JO (1978) Role of the periaqueductal grey matter and spinal 5-hydroxytryptaminergic pathways in morphine analgesia: effects of lesions and 5-hydroxytryptamine depletion. $\mathrm{Br} \mathbf{J}$ Pharmacol 63:159-165.

Dennis SG, Melzack R (1983) Pain modulation by serotonergic agents and morphine as measured by three pain tests. Exp Neurol 69:260270.

Fields HL, Basbaum AI, Clanton CH, Anderson SD (1977) Nucleus raphe magnus inhibition of spinal dorsal horn neurons. Brain Res 126:441-453.

Fields HL, Bry J, Hentall ID, Zorman G (1983a) The activity of neurons in the rostral medulla of the rat during withdrawal from noxious heat. J Neurosci 3:254-252.

Fields HL, Vanegas H, Hentall ID, Zorman G (1983b) Evidence that disinhibition of brain stem neurones contributes to morphine analgesia. Nature 306:684-686.

Fields HL, Heinricher MM, Mason P (1991) Neurotransmitters in nociceptive modulatory circuits. Annu Rev Neurosci 14:219-245.

Fornal CA, Jacobs BL (1988) Physiological and behavioral correlates of serotonergic single-unit activity. In: Neuronal serotonin (Osborne NN, Hamon M, eds), pp 305-345. New York: Wiley.

Fornal C, Auerbach S, Jacobs BL (1985) Activity of serotonin-containing neurons in nucleus raphe magnus in freely moving cats. Exp Neurol 88:590-608.

Gamble GD, Milne RJ (1990) Behavioral modification of bulbospinal serotonergic inhibition and morphine analgesia. Brain Res 521:167174.

Grahn DA, Heller CH (1989) Activity of most rostral ventromedial medulla neurons reflect EEG/EMG pattern changes. Am $\mathbf{J}$ Physiol 257:R1496-R1505.

Hammond DL, Yaksh TL (1984) Antagonism of stimulation produced antinociception by intrathecal administration of methysergide or phentolamine. Brain Res 298:329-337.

Heinricher MM, Morgan MM, Fields HL (1992) Direct and indirect actions of morphine on medullary neurons that modulate nociception. Neuroscience 3:533-543.

Herkenham M (1987) Mismatches between neurotransmitter and receptor localization in brain: observations and implications. Neuroscience 23:1-38.

Jacobs BL, Fornal CA (1991) Activity of brain serotonergic neurons in the behaving animal. Pharmacol Reviews 43:563-578.

Jacobs BL, Wilkinson LO, Fornal CA (1990) The role of brain serotonin: a neurophysiologic perspective. Neuropsychopharmacology $3: 473-478$.

Jensen TS, Yaksh TL (1984) Spinal monoamine and opiate systems partly mediate the antinociceptive effects of glutamate microinjected at brainstem sites. Brain Res 321:287-297.

Jensen TS, Yaksh TL (1986) I. Comparison of the antinociceptive action of morphine in the periaqueductal gray, medial and paramedial medulla in rat. Brain Res 363:99-113.

Jensen TS, Yaksh TL (1989) Comparison of the antinociceptive effect of morphine and glutamate at coincidental sites in the periaqueductal gray and medial medulla in rats. Brain Res 476:1-9.

Jordan LM, Kenshalo DR Jr, Martin RF, Haber IH, Willis WD (1978) Depression of primate spinothalamic tract neurons by iontophoretic application of 5-hydroxytryptamine. Pain 5:135-142.

Kwiat GC, Basbaum AI (1992)The origin of brainstem noradrenergic and serotonergic projections to the spinal cord dorsal horn in the rat. Somatosens Mot Res 9:157-173.

LeBars D (1988) Serotonin and pain. In: Neuronal serotonin (Osborne NN, Hamon M, eds), pp 171-226. New York: Wiley.

Levy RA. Proudfit HK (1979) Analgesia produced by microinjections of baclofen and morphine at brainstem sites. Eur $J$ Pharmacol 57: $43-55$.

Light AR, Casale EJ, Menetrey DM (1986) The effects of focal stimulation in nucleus raphe magnus and periaqueductal gray on intracellularly recorded neurons in spinal laminae I and II. J Neurophysiol 56:555-571.

Martin G, Montagne-Clave J, Oliveras JL (1992) Involvement of ventromedial medulla "multimodal, multireceptive neurons" in opiate spinal descending control system: a single unit study of the effect of morphine in the awake, freely moving rat. J Neurosci 12:1511-1522.

Mason P, Strassman A, Maciewicz R (1988) Serotonin immunocytochemistry of physiologically characterized raphe magnus neurons. Exp Brain Res 73:1-7.
Mason P, Floeter MK, Fields HL (1990) Somatodendritic morphology of on- and off-cells in the rostral ventromedial medulla. J Comp Neurol 301:23-43.

Matos FF, Rollema H, Brown J, Basbaum AI (1992) Do opioids evoke the release of serotonin in the spinal cord? An in vivo microdialysis study of the regulation of extracellular serotonin in the rat. Pain 48: 439-347.

McGaraughty S, Reinis S, Tsoukatos J (1993) Two distinct unit activity responses to morphine in the rostral ventromedial medulla of awake rats. Brain Res 604:331-333.

Mohrland JS, Gebhart GF (1980) Effect of selective destruction of serotonergic neurons in nucleus raphe magnus on morphine induced antinociception. Life Sci 27:2627-2632.

Moore RY (1981) The anatomy of central serotonin neuron systems in the rat brain. In: Serotonin neurotransmission and behavior (Jacobs BL, Gelperin A, eds), pp 35-71. Cambridge, MA: MIT Press.

Oliveras JL, Redjemi F, Giulbaud G, Besson JM (1975) Analgesia induced by electrical stimulation of the inferior centralis nucleus of the raphe in the cat. Pain 1:139-145.

Oliveras JL, Bourgoin S, Hery F, Besson JM, Hamon M (1977) The topographical distribution of serotonergic terminals in the spinal cord of the cat: biochemical mapping by the combined use of microdissection and microassay procedures. Brain Res 138:393-406.

Oliveras JL, Martin G, Montagne J, Vos B (1990) Single unit activity at ventromedial medulla level in the awake, freely moving rat: effects of noxious heat and light tactile stimuli onto convergent neurons. Brain Res 506:19-30.

Oliveras JL, Martin G, Montagne-Clavel J (1991) Drastic changes of ventromedial medulla neuronal properties induced by barbiturate anesthesia. II. Modifications of the single unit activity produced by Brevital, a short-acting barbiturate in the awake, freely moving rat. Brain Res 563:251-260.

Pan ZZ, Wessendorf MW, Williams JT (1993) Modulation by serotonin of the neurons in rats nucleus raphe magnus in vitro. Neuroscience 54:421-430.

Paxinos G, Watson C (1986) The rat brain in stereotaxic coordinates. New York: Academic.

Randic M, Yu HY(1976) Effects of 5-hydroxytryptamine and bradykinin in cat dorsal horn neurones activated by noxious stimuli. Brain Res 111:197-203.

Rivot JP, Chaouch A, Besson JM (1980) Nucleus raphe magnus and the responses of rat dorsal horn neurons to unmyelinated fiber inputs: partial involvement of serotonergic pathways. J Neurophysiol 44: $1039-1057$.

Rivot JP, Pointis D, Besson JM (1988) In vivo electrachemical detection of 5-hydroxyindole within the trigeminal nucleus caudalis of freely moving rats: the effect of morphine. Brain Res 463:275-283.

Romandini S, Pich EM, Esposito E, Kruszewsda AZ, Samanin R (1986) The effect of intracerebroventricular 5,7 dihydroxytryptamine on morphine analgesia is time-dependent. Life Sci 38:869-875.

Ruda MA, Gobel S (1980) Ultrastructural characterization of axonal endings in the substantia gelatinosa which take up $\left[{ }^{3} \mathrm{H}\right]$ serotonin. Brain Res 184:57-83

Sessle BJ, Hu JW (1981) Raphe-induced suppression of the jaw-opening reflex and single neurons in trigeminal subnucleus oralis, and influence of naloxone and subnucleus caudalis. Pain 10:19-36.

Sessle BJ, Hu JW, Dubner R, Lucier GE (1981) Functional properties of neurons in cat trigeminal subnucleus caudalis (medullary dorsal horn). II. Modification of response to noxious and non-noxious stimulation by periaqueductal gray, raphe magnus, cerebellar cortex, and afferent influences, and effect of naloxone. J Neurophysiol 45:193 207.

Shiomi HH, Murakami H, Takagi H (1978) Morphine analgesia and the bulbospinal serotonergic system: increase in concentration of 5 -hydroxyindoleacetic acid in rat spinal cord. Eur $\mathbf{J}$ Pharmacol 52 : 335-344.

Skagerberg G, Bjorklund (1985) Topographic principles in the spinal projections of serotonergic and non-serotonergic brainstem neurons in the rat. Neuroscience 15:445-480.

Valtschanoff JG, Weinberg RJ, Rustioni A (1992) NADPH diaphorase in the spinal cord of rats. J Comp Neurol 321:209-222.

Vanegas H, Barbaro NM, Fields HL (1984a) Midbrain stimulation inhibits tail-flick only at currents sufficient to excite rostral medullary neutrons. Brain Res 321:127-133. 
Vanegas H, Barbaro NM, Fields HL (1984b) Tail flick related activity in medullospinal neurons. Brain Res 321:135-141.

Vasko MR, Vogt M (1982) Analgesia, development of tolerance, and 5-hydroxytryptamine turnover in the rat after cerebral and systemic administration of morphine. Neuroscience 7:1215-1225.

Vogt M (1974) The effect of lowering 5-hydroxytryptamine content of the rat spinal cord on analgesia produced by morphine. J Physiol (Lond) 236:483-498.

Wallace JA, Petrusz P, Lauder JM (1982) Serotonin immunocytochemistry in the adult and developing brain: methodological and pharmacological considerations. Brain Res Bull 9:117-129.

Weil-Fugazza J, Godefroy F, Coudert D, Besson JM (1981) Morphine analgesia and newly synthesized 5-hydroxytryptamine in the dorsal and the ventral halves of the spinal cord in rats. Brain Res 214:440444.

Wessendorf MW, Anderson EG (1983) Single unit studies of identified bulbospinal serotonergic units. Brain Res 279:93-103.

Yaksh TL, Wilson TR (1979) Spinal serotonin terminal system mediates antinociception. J Pharmacol Exp Ther 208:446-453.

Yezierski RP, Wilcox TK, Willis WD (1982) The effects of serotonin antagonists on the inhibition of primate spinothalamic tract cells produced by stimulation of the nucleus raphe magnus or periaqueductal gray. J Pharmacol Exp Ther 220:266-277. 